\title{
Some effects of multiple sclerosis on speech perception in noise: Preliminary findings
}

\author{
M. Samantha Lewis, PhD; ${ }^{1-2 *}$ David J. Lilly, PhD; ${ }^{1}$ Michele Hutter, MS; ${ }^{1}$ Dennis N. Bourdette, MD; ${ }^{3-5}$ \\ Julie Saunders, RN, MSN, ANP; ${ }^{3-4}$ Stephen A. Fausti, PhD $^{1-2}$ \\ ${ }^{1}$ Department of Veterans Affairs (VA) National Center for Rehabilitative Auditory Research, Portland VA Medical Center \\ (VAMC), Portland, OR; Departments of ${ }^{2}$ Otolaryngology and ${ }^{3}$ Neurology, Oregon Health \& Science University, Port- \\ land, OR; ${ }^{4}$ Multiple Sclerosis Center of Oregon, Oregon Health \& Science University, Portland, OR; ${ }^{5}$ Department of \\ Neurology, Portland VAMC, Portland, OR
}

\begin{abstract}
The present investigation examined speech perception in noise of adults with and without multiple sclerosis (MS). Institute of Electrical and Electronic Engineers (IEEE) sentences were presented at a constant level of $65 \mathrm{dBA} \mathrm{L} \mathrm{L}_{\mathrm{eq}}$ (equivalent continuous noise level [4 $\mathrm{dB}$ exchange rate]) from a loudspeaker located at 0-degree horizontal azimuth and $1.2 \mathrm{~m}$ from the study participant. Uncorrelated multitalker babble was presented from four loudspeakers positioned at 45-, 135-, 225-, and 315-degree azimuths and $1.7 \mathrm{~m}$ from the study participant. The starting presentation level for the babble was $55 \mathrm{dBA} \mathrm{L}_{\mathrm{eq}}$. The level of the babble was increased systematically in $1 \mathrm{~dB}$ steps until the subject obtained $0 \%$ key words correct on the IEEE sentences. Results revealed a significant difference in speech perception between the two groups at nine signal-to-noise ratios. Some clinical implications of these results are discussed.
\end{abstract}

Key words: adults, auditory function, auditory processing, hearing, IEEE sentences, multiple sclerosis, multitalker babble, noise, signal-to-noise ratio, speech perception.

\section{INTRODUCTION}

Multiple sclerosis (MS) is an inflammatory disease of the central nervous system (CNS) that affects over 400,000 U.S. citizens and almost 2,500,000 individuals worldwide [1]. MS causes damage to myelin, the fatty coating on nerve fibers that aids in transmission of the electrical impulses within the nervous system, and to the nerve fibers themselves. This damage slows, distorts, or halts the transmission of the electrical impulses transmitted throughout the CNS and results in many of the symptoms associated with MS, such as fatigue, slurred speech, and blurred vision.

Abbreviations: ANOVA $=$ analysis of variance, CNS = central nervous system, EDSS = Expanded Disability Status Scale, $\mathrm{HL}=$ hearing level, IEEE = Institute for Electrical and Electronic Engineers, $\mathrm{L}_{\mathrm{eq}}=$ equivalent continuous noise level ( $4 \mathrm{~dB}$ exchange rate), $\mathrm{MS}=$ multiple sclerosis, $\mathrm{PTA}=$ pure tone average, RR\&D = Rehabilitation Research and Development, SD = standard deviation, $\mathrm{SIN}=$ speech in noise, SNR = signal-tonoise ratio, $\mathrm{SPL}=$ sound pressure level, VA $=$ Department of Veterans Affairs, VAMC = VA medical center, WRS = word recognition scores.

* Address all correspondence to M. Samantha Lewis, PhD; VA National Center for Rehabilitative Auditory Research, Portland VAMC, 3710 SW U.S. Veterans Hospital Road, Portland, OR 97207; 503-220-8262, ext. 51996; fax: 503220-3439. Email: Michele.Lewis3@med.va.gov

DOI: 10.1682/JRRD.2004.09.0113 
The incidence of hearing loss associated with MS varies, with estimates ranging from 1 to 86 percent [2]. When a loss in pure tone sensitivity does occur, it generally is considered mild in nature [3]. Despite this, 40 to 60 percent of MS patients with normal pure tone thresholds complain of difficulty hearing [4]. These findings are not surprising, given that MS primarily affects the CNS. In fact, abnormal auditory-evoked potentials have been reported in 32 to 93 percent of MS patients [4-7]. The most common abnormalities noted in these studies include absent or abnormally low wave $\mathrm{V}$ amplitude and the increased III-V interwave latency. Additionally, other studies have reported abnormal auditory processing in subjects with MS, such as problems with dichotic listening tasks and auditory temporal processing [8-10].

Because problems understanding speech in background noise are characteristic of individuals with auditory processing problems and disorders of the central auditory nervous system, one might postulate that individuals with MS would also have this type of deficit. In fact, several studies have revealed that a high percentage (33\%-69\%) of individuals with MS experience difficulty understanding speech when it is presented with a competing stimulus $[3,11]$. Unfortunately, these prior studies were conducted either under earphones, monaurally, with a small sample size, or without the use of a control group. With these considerations in mind, the National Center for Rehabilitative Auditory Research at the Portland Department of Veterans Affairs (VA) Medical Center (VAMC) is examining speech perception in noise for adults both with and without MS in a diffuse listening situation. This diffuse listening situation more closely represents real-world listening environments and, as such, may more closely capture the subjective auditory complaints reported by individuals with MS. This article presents interim results obtained thus far from this ongoing investigation.

\section{METHODS}

\section{Subjects}

We evaluated two groups of subjects in this investigation: subjects with MS and control subjects who were matched to the subjects with MS in age, sex, and four frequency pure tone averages (PTAs). These study participants were recruited from the Portland VAMC and the Oregon Health \& Science University in Portland, Oregon.
Thus far, 23 subjects with MS have been evaluated, of whom 57 percent were male and 43 percent were female. These subjects ranged in age from 40 to 63 years, with a mean age of 51 years ( \pm 7 years standard deviation [SD]). Thirty control subjects have been evaluated, of whom 50 percent were male and 50 percent were female. These subjects ranged in age from 22 to 63 years, with a median age of 51 years ( \pm 11 years $S D)$. A one-way analysis of variance (ANOVA) revealed no significant difference $(p>0.05)$ between these two subject groups in age ( $p=0.97$ ), word recognition scores (WRSs) for the right $(p=0.67)$ and left ( $p=0.10)$ ears, and four frequency PTAs in the right $(p=$ $0.17)$ and left $(p=0.13)$ ears.

All study participants met the following inclusion criteria: (1) age 21 to 65 years, (2) absence of current major disease or disorder (besides MS) as reported by the patient or as noted in the medical record, (3) absence of dementia or other neurological conditions as reported by the patient or as noted in the medical record, and (4) absence of a significant language barrier as assessed informally during the interview process.

The subjects with MS also met the following additional inclusion criteria: (1) a clinical or laboratory diagnosis of "definite MS" [12], (2) a diagnosis of relapsingremitting, primary progressive, or secondary progressive MS, (3) a Kurtzke Expanded Disability Status Scale (EDSS) of 0 to 7.0, (4) no history of clinical relapse or change in EDSS score for 3 months before joining the study, and (5) a recent brain magnetic resonance imaging (MRI) scan showing at least three white-matter lesions on T2-weighted images consistent with MS. Subjects completed all test sessions within 1 month.

\section{Auditory Symptoms}

At the time they enrolled in the study, all participants completed a questionnaire regarding their hearing and health histories. Included was a question that asked whether the individual noted any difficulty with his or her hearing. If the patient answered affirmatively, he or she was considered to have subjective auditory deficits and was asked further questions regarding difficulty hearing, such as time of onset; if the hearing loss was associated with a particular illness, accident, or special circumstance; which ear(s) were affected; etc.

\section{Speech Stimuli}

The Institute of Electrical and Electronic Engineers (IEEE) Sentence Intelligibility (SI) test served as the speech stimuli [13]. This test consists of 72 lists of 10 sentences 
each. Each sentence contains five key words. This sentence material has been shown to be more difficult than other sentence tests because it contains reduced contextual cues [1415]. These sentences were stored as sound files on a computer (Apple Macintosh Centris 650, Cupertino, California). The sounds were presented and attenuated with the use of custom-produced software on a second computer (Hewlett-Packard [Houston, Texas] with a Pentium 4 processor) and a programmable attenuator (Tucker-Davis Technologies, PA4, Alachua, Florida). The output of the programmable attenuator was amplified (Crown, model CP, 660, Elkhart, Illinois), and delivered to a loudspeaker (JBL Monitor 28, Northridge, California) located at $0^{\circ}$ azimuth and $1.2 \mathrm{~m}$ from the study participant. Lilly et al. give greater details regarding this experimental setup.

\section{Noise Competition}

Uncorrelated multitalker babble served as the noise competition. Sperry et al. reported that the use of speech materials has a more adverse masking effect on speech perception than other nonmeaningful noises [16]. Additionally, this type of noise competition has been shown to effectively mask speech materials for individuals both with and without hearing loss [17-18]. This noise competition was presented from four audio tracks (one for each loudspeaker) stored on two separate compact disc recordings. The noise competition was also presented and attenuated with custom-produced software on the second computer and the programmable attenuator. The output of the programmable attenuator was amplified and delivered to four JBL loudspeakers located $45^{\circ}, 135^{\circ}$, $225^{\circ}$, and $315^{\circ}$ azimuths and $1.7 \mathrm{~m}$ away from the study participant. Lilly et al. also give greater details regarding this experimental setup. ${ }^{*}$

\section{Procedures}

Speech perception in noise was conducted in a doublewalled Acoustic Systems (ETS-Lindgren Co, Cedar Park, Texas) sound-treated chamber (1.96 m high $\times 2.6 \mathrm{~m}$ wide $\times$ $2.4 \mathrm{~m}$ long). The IEEE sentences were presented at a constant level of $65 \mathrm{dBA} \mathrm{L}_{\mathrm{eq}}$ (equivalent continuous noise level [4 $\mathrm{dB}$ exchange rate]) from a loudspeaker positioned at $0^{\circ}$ azimuth and located $1.2 \mathrm{~m}$ from the study participant. Uncorrelated multitalker babble was presented from four loudspeakers positioned at $45^{\circ}, 135^{\circ}, 225^{\circ}$, and $315^{\circ}$ azimuths and located $1.7 \mathrm{~m}$ from the study participant. All the

\footnotetext{
*Personal communication, David Lilly, 2006.
}

loudspeakers were at a height level with the subject's ears. The starting presentation level for the multitalker babble was $55 \mathrm{dBA} \mathrm{L} \mathrm{L}_{\mathrm{eq}}$. The level of the noise was increased systematically in $1 \mathrm{~dB}$ steps until the subject obtained 0 percent key words correct on the IEEE sentences. To ensure consistency of the speech and noise signals, regular calibrations were made from the location of the subject's head with the participant absent using a sound level meter (Brüel \& Kjaer, Type 2238 Mediator, Norcross, Georgia). To reduce the potential for order effects, we randomized the IEEE sentence lists. None of the sentence lists was repeated with any given subject to prevent potential learning effects.

\section{RESULTS}

\section{Subjects}

Pure tone air-conduction and bone-conduction hearing thresholds were obtained bilaterally for both groups of subjects. For the MS subjects, mean PTAs were consistent with normal hearing in the lower test frequencies, sloping to a mild sensorineural hearing loss bilaterally in the higher test frequencies. The group of subjects without MS had normal hearing bilaterally. These results are presented in Figures 1 and 2. We obtained WRSs bilaterally for all study participants at $25 \mathrm{~dB}$ above the speech reception threshold (SRT) (dB HL [hearing level] per American National Standards Institute standards [19]) for the test ear using recorded Central Institute for the Deaf (CID) W-22 word lists (VA disk 1.1 [20]). Test results revealed mean WRS ( \pm 1 SD) of 92.9 percent $( \pm 8.7 \%)$ and 88.9 percent $( \pm 14.3 \%)$ for the right and left ears, respectively, for the group with MS, and 93.9 percent $( \pm 6.9 \%)$ and 93.7 percent $( \pm 6.4 \%)$ for the right and left ears for the group without MS. Independent samples $t$-tests revealed no significant difference $(p>0.05)$ between the two ears in either experimental group, for the four-frequency PTA and the WRS.

\section{Auditory Symptoms}

Of the subjects with MS, 70 percent reported difficulty hearing, 17 percent reported no difficulty hearing, and 13 percent were unsure. Of the control subjects, 33 percent reported difficulty hearing, 63 percent reported no difficulty hearing, and 1 percent was unsure. A chisquare statistic revealed a statistically significant difference in subjective complaints of auditory symptoms between the two groups $(p<0.05)$, with the subjects with MS reporting greater difficulty hearing. Of the subjects 


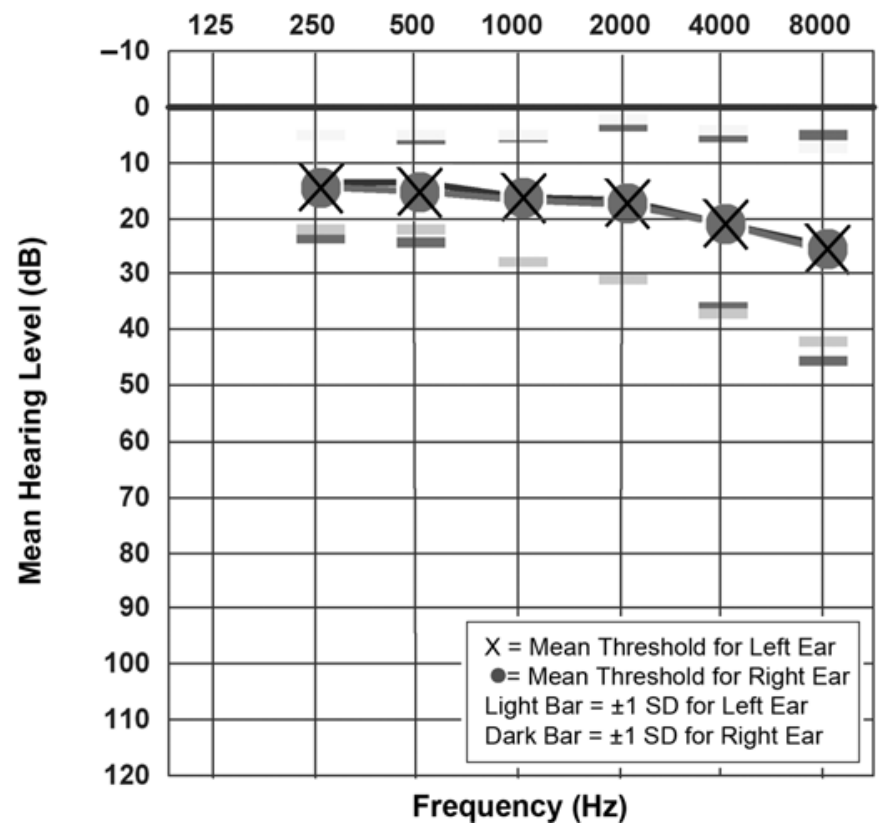

Figure 1.

Mean pure tone thresholds ( \pm 1 standard deviation [SD]) obtained for right and left ears in subjects with multiple sclerosis. Audiogram taken from American National Standard Specification for Audiometers, American National Standards Institute, Inc. New York: Acoustical Society of America; 1996.

with MS who reported problems with their hearing, 40 percent reported problems with both ears, 20 percent reported problems with the left ear, and 40 percent were unsure. All these subjects reported that their difficulty hearing began at least 3 years prior, with 33 percent of these subjects attributing their difficulty hearing to MS. Only one individual reported that his difficulty hearing was related to an exacerbation of MS symptoms.

\section{Speech Perception in Noise}

The mean percentage of key words correct $( \pm 1$ SD) at each signal-to-noise ratio (SNR) is presented in Figure 3. This figure illustrates that, at some SNRs, a difference exists in speech perception in noise between the group of subjects with MS and the group without MS. The group with MS appears to have performed more poorly than the group without MS at these SNRs. We analyzed the data using a two-way ANOVA with repeated measures on one factor. Both main effects and the interaction were significant: Groups $F_{1,51}=7.39(p<0.009)$, SNR $F_{25,1275}=$ $475.74(p<0.0001)$, SNR $\times$ Groups $F_{25,1275}=2.26(p<$ $0.0004)$. Because the interaction term was significant and

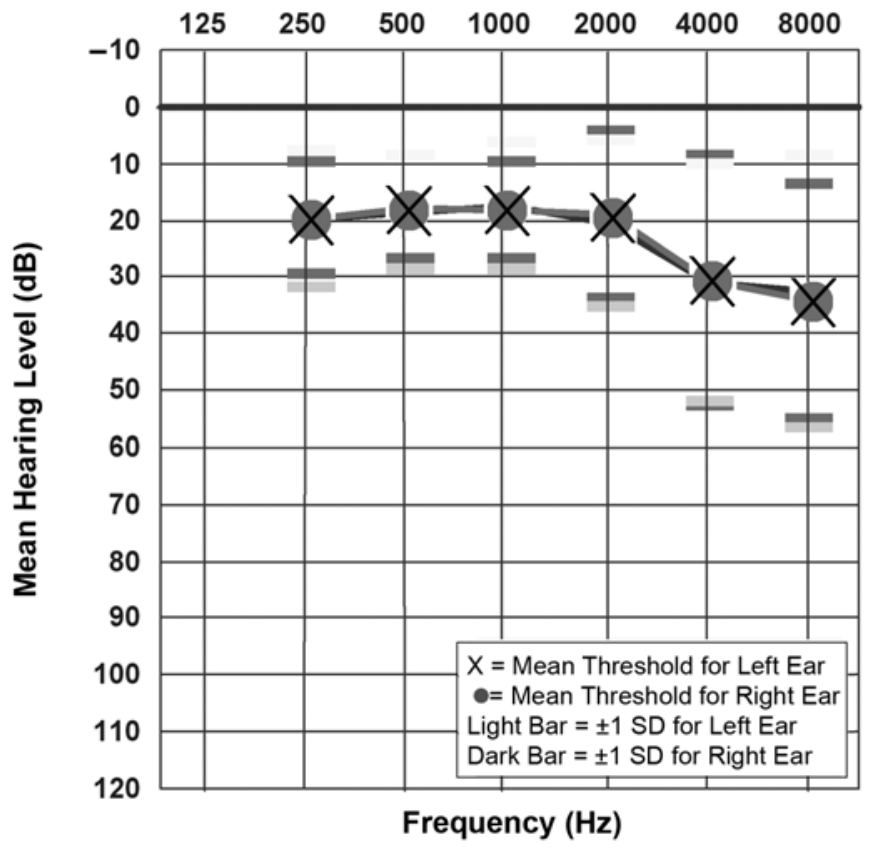

Figure 2.

Mean pure tone thresholds ( \pm 1 standard deviation [SD]) obtained for right and left ears in subjects without multiple sclerosis. Audiogram taken from American National Standard Specification for Audiometers, American National Standards Institute, Inc. New York: Acoustical Society of America; 1996.

our main intent in this study was to determine at exactly which SNR levels the groups differed, we performed an analysis of simple effects [21]. The groups differed significantly at $p=0.05$ at SNR levels $0 \mathrm{~dB},-8 \mathrm{~dB},-9 \mathrm{~dB}$, and $-10 \mathrm{~dB}$; they differed at $p=0.01$ at SNR levels $-1 \mathrm{~dB},-3$ $\mathrm{dB},-4 \mathrm{~dB},-5 \mathrm{~dB}$, and $-6 \mathrm{~dB}$ (Table).

The slope of the curve from $-11 \mathrm{~dB}$ SNR to $+2 \mathrm{~dB}$ SNR, portrayed in Figure 3, for the group of subjects with MS was 8.0 percent per decibel SNR. For the subjects without MS, the slope of these same data points was 7.9 percent per decibel SNR. An independent samples $t$ test revealed no significant difference $(p>0.05)$ in slope between the two experimental groups.

\section{Subjective Auditory Complaints and Speech Perception in Noise}

Correlation analyses were conducted to determine whether a relationship existed between subjective auditory complaints and performance on the speech perception task. These analyses revealed that for subjects both with and without MS, a significant negative correlation existed $(p<0.05)$ between subjective auditory complaints 
Table.

Summary of statistically significant signal-to-noise ratio (SNR) levels.

\begin{tabular}{rccc}
$\begin{array}{c}\text { SNR } \\
\text { (dB) }\end{array}$ & $\begin{array}{c}\text { \% Key Words } \pm \text { 1 SD Correct for } \\
\text { Subjects with MS }\end{array}$ & $\begin{array}{c}\text { \% Key Words } \pm \text { 1 SD Correct for } \\
\text { Subjects without MS }\end{array}$ & $\begin{array}{c}\text { Difference in \% Key Words Correct } \\
\text { Between Groups }\end{array}$ \\
\hline $0^{*}$ & $87 \pm 22$ & $96 \pm 9$ & 9 \\
$-1^{\dagger}$ & $85 \pm 21$ & $96 \pm 9$ & 11 \\
$-3^{\dagger}$ & $69 \pm 32$ & $86 \pm 16$ & 17 \\
$-4^{\dagger}$ & $62 \pm 33$ & $80 \pm 20$ & 18 \\
$-5^{\dagger}$ & $56 \pm 34$ & $73 \pm 23$ & 17 \\
$-6^{\dagger}$ & $45 \pm 35$ & $59 \pm 24$ & 14 \\
$-8^{\dagger}$ & $19 \pm 18$ & $29 \pm 24$ & 10 \\
$-9^{\dagger}$ & $12 \pm 15$ & $22 \pm 27$ & 10 \\
$-10^{*}$ & $4 \pm 9$ & $13 \pm 19$ & 9 \\
\hline SD $=$ standard deviation, MS $=$ multiple sclerosis. & \\
${ }_{p}^{\dagger} p=0.05$ & & & \\
\hline$p=0.01$ & & & \\
\hline \hline
\end{tabular}

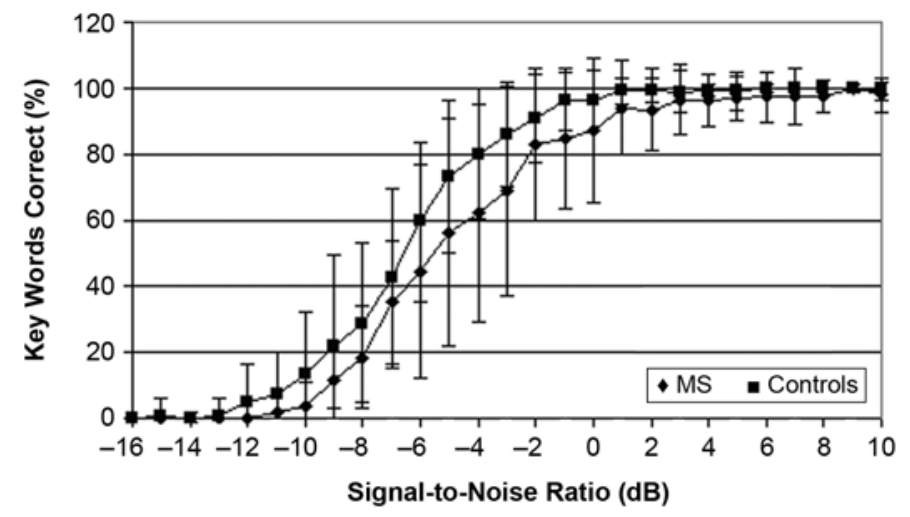

Figure 3.

Mean percentage of key words correct ( \pm 1 standard deviation at each signal-to-noise ratio for subjects with multiple sclerosis (MS) and subjects without MS (controls).

and the number of key words correct at the following SNRs: $-1 \mathrm{~dB},-3 \mathrm{~dB},-4 \mathrm{~dB},-5 \mathrm{~dB},-6 \mathrm{~dB},-7 \mathrm{~dB},-8 \mathrm{~dB}$, $-9 \mathrm{~dB},-10 \mathrm{~dB}$, and $-11 \mathrm{~dB}$. In other words, the subjects who reported greater subjective auditory complaints performed more poorly on the speech perception in noise task at these SNR levels.

\section{CONCLUSIONS}

These results suggest that, at particular SNRs, a statistically significant difference in speech perception in noise exists between the group of subjects with MS and the group without MS. At each of these SNRs, the group with MS performed more poorly than the group without MS. This result is not surprising, given that a greater majority of the subjects with MS complained of difficulty hearing compared with the group without MS. Recall that 70 percent of the subjects with MS reported difficulty hearing, whereas only 33 percent of the subjects without MS reported difficulty hearing. Furthermore, these auditory complaints were significantly correlated with poor performance on the speech perception in noise task at most of these SNR levels.

\section{Limitations}

Despite the significant findings reported in this investigation, several study limitations may have influenced the results obtained. First, a diversity is recognized among patients regarding symptoms associated with MS, depending on the sites and amount of damage in the CNS [1]. Additionally, the symptoms associated with MS can fluctuate daily in the same individual. These withinsubject and between-subject variabilities may have affected the results obtained in this investigation by either under- or overreporting the auditory problems experienced by this population.

Similarly, a relatively small number of subjects with MS were evaluated in this study. Recall that the sample size for the group of subjects with MS was 23. Because the symptoms associated with MS are highly variable between patients, this small sample size may have exaggerated or minimized the auditory problems reported here. One should note, however, that this study is still ongoing. When the study concludes in March 2006, we anticipate 
that data will have been collected on 50 subjects with MS and 50 subjects without MS. The final results of this investigation may add to what we know about the auditory characteristics of an MS population.

In this testing paradigm, large SDs were obtained at certain SNRs. For the subjects with MS, the SDs ranged from 0 to 35 percent. For the subjects without MS, the SDs ranged from 0 to 27 percent. This finding suggests that the average scores are quite variable across SNRs for both groups of subjects. This finding corresponds with results obtained by Bentler [22]. In that investigation, Bentler also showed large SDs across IEEE sentence lists for both subjects with normal hearing and subjects with hearing impairment $(0 \%-37 \%)$. The large SDs obtained with this test material may minimize the differences between test groups and, ultimately, the auditory problems experienced by the MS population in comparison with a control group.

A major criticism of tests that use the IEEE sentences (e.g., the Speech in Noise [SIN] test and the QuickSIN) is the lack of equivalency between some of the IEEE sentence lists. Bentler reported a significant difference between some of the sentence lists for subjects with normal hearing at the $53 \mathrm{~dB}$ sound pressure level (SPL) and $83 \mathrm{~dB}$ SPL presentation levels [22]. At the $53 \mathrm{~dB}$ SPL presentation level, the following sentence lists were considered equivalent: (1) lists 1 and 2; (2) lists 5 and 6; and (3) lists 3, 4, and 8 . At the $83 \mathrm{~dB}$ SPL presentation level, the following sentence lists were considered equivalent: (1) lists 1,2 , and 9 ; (2) lists 3, 4, and 5; and (3) lists 6 and 8. Because all these IEEE sentence lists were used in the present investigation, one cannot rule out that this lack of list equivalency affected the test results. This lack of list equivalency may have minimized or exaggerated the differences between the two test groups, depending on which lists were administered to the various subjects.

\section{Summary}

In general, these interim results indicate that patients with MS tend to report greater difficulty hearing in their everyday listening environments and that they do not understand speech in background noise as well as individuals without MS. Moreover, these two measures are significantly correlated. One should note that these hearing difficulties occur even in the presence of essentially normal hearing thresholds. These results suggest that clinicians need to query their patients with MS regarding their hearing ability so they can properly assess and assign rehabilitation. One should also note that preliminary results suggest that the use of frequency-modulation technology may viably improve speech perception in noise for these individuals [23] and should be considered as a rehabilitation option for patients with MS that experience difficulty hearing in adverse listening situations. Our future investigations will examine other possible rehabilitation options for this population.

\section{ACKNOWLEDGMENTS}

Portions of this work have been presented at the 16th Annual American Academy of Audiology Convention, the 2004 Association of Research in Otolaryngology Annual Meeting, and the 2004 International Hearing Aid Research Conference.

This material was based on work supported by the VA RR\&D Service, grant B2568R; VA RR\&D Associate Investigator Award, grant C3293H; and the VA RR\&D National Center for Auditory Research, grant C2659C.

\section{REFERENCES}

1. National Multiple Sclerosis Society [homepage on the Internet]. New York (NY): National Multiple Sclerosis Society; c2006 [updated 2006 Feb 21; cited 2004 Jul 22]. Available from: http://www.nationalmssociety.org/

2. Mustillo P. Auditory deficits in multiple sclerosis: A review. Audiology. 1984;23(2):145-64. [PMID: 6372768]

3. Noffsinger D, Olsen WO, Carhart R, Hart CW, Sahgal V. Auditory and vestibular aberrations in multiple sclerosis. Acta Otolarynogol Suppl. 1972;303:1-63. [PMID: 4542210]

4. Musiek F, Gollegly K, Kibbe KS, Reeves AG. Electrophysiologic and behavioral auditory findings in multiple sclerosis. Am J Otol. 1989;10(5):343-50. [PMID: 2817103]

5. Chiappa KH, Harrison JL, Brooks EB, Young RR. Brainstem auditory evoked responses in 200 patients with multiple sclerosis. Ann Neurol. 1980;7(2):135-43. [PMID: 7369720]

6. Hannley M, Jerger JF, Rivera VM. Relationships among auditory brainstem responses, masking level differences and the acoustic reflex in multiple sclerosis. Audiology. 1983;22(1):20-33. [PMID: 6830528]

7. Hendler T, Squires NK, Moore JK, Coyle PK. Auditory evoked potentials in multiple sclerosis: Correlation with magnetic resonance imaging. J Basic Clin Physiol Pharmacol. 1996;7(3):245-78. [PMID: 8910140] 
8. Jacobson JT, Deppe U, Murray TJ. Dichotic paradigms in multiple sclerosis. Ear Hear. 1983;4(6):311-17. [PMID: 6653936]

9. Hendler T, Squires NK, Emmerich DS. Psychophysical measures of central auditory dysfunction in multiple sclerosis: Neurophsysiological and neuroanatomical correlates. Ear Hear. 1990;11(6):403-16. [PMID: 2073974]

10. Gadea M, Marti-Bonmati L, Arana E, Espert R, Casanova V, Pascual A. Dichotic listening and corpus callosum magnetic resonance imaging in relapsing-remitting multiple sclerosis with emphasis on sex differences. Neuropsychology. 2002;16(2):275-81. [PMID: 11949719]

11. Dayal VS, Tarantino L, Swisher LP. Neuro-otologic studies in multiple sclerosis. Laryngoscope. 1966;76(11):1798-1809. [PMID: 5924326]

12. Poser CM, Paty DW, Scheinberg L, McDonald WI, Davis FA, Ebers GC, Johnson KP, Sibley WA, Silderberg DH, Tourtellotte WW. New diagnostic criteria for multiple sclerosis: Guidelines for research protocols. Ann Neurol. 1983; 13(3):227-31. [PMID: 6847134$]$

13. Institute of Electronic and Electrical Engineers. IEEE recommended practice for speech quality measures. New York (NY): IEEE; 1969.

14. Grant KW, Braida LD. Evaluating the articulation index for auditory-visual input. J Acoust Soc Am. 1991;89(6): 2952-60. [PMID: 1918633] Erratum in: J Acoust Soc Am. 1991;90(4 Pt 1): 2202.

15. Villchur E. Multichannel compression processing for profound deafness. J Rehabil Res Dev. 1987;24(4):135-48. [PMID: 3430373]
16. Sperry JL, Wiley TL, Chial MR. Word recognition performance in various background competitors. J Am Acad Audiol. 1997;8(2):71-80. [PMID: 9101453]

17. Snell KB, Mapes FM, Hickman ED, Frisnia DR. Word recognition in competing babble and the effects of age, temporal processing, and absolute sensitivity. J Acoust Soc Am. 2002;112(2):720-27. [PMID: 12186051]

18. Souza PE, Turner CW. Masking of speech in young and elderly listeners with hearing loss. J Speech Hear Res. 1994;37(3):655-61. [PMID: 8084195]

19. Acoustical Society of America. American national standard specification for audiometers. New York (NY): American National Standards Institute, Inc; 1996.

20. Wilson R, Preece J. Development of a compact disc for speech audiometry. Audiol Today. 1990;2(4):24-26.

21. Winer BJ, Brown DR, Michels KM. Statistical principles in experimental design. 3rd ed. Columbus $(\mathrm{OH})$ : McGrawHill, Inc; 1991.

22. Bentler RA. List equivalency and test-retest reliability of the Speech in Noise test. Am J Audiol. 2000;9(2):84-100. [PMID: 11200196]

23. Lewis MS, Hutter M, Lilly D, Bourdette DN, Saunders J, Fausti S. Frequency modulation (FM) technology as a method for improving speech perception in noise for patients with multiple sclerosis. J Am Acad Audiol. In press 2006.

Submitted for publication September 1, 2004. Accepted in revised form January 31, 2005. 